observations, concludes that there is still a great deal to unravel. Depersonalisation disorder is notoriously resistant to treatment but promising results are claimed for treatment with either lamotrigine, the combination of a selective serotonin reuptake inhibitor antidepressant and the stimulant modafinil, or opioid antagonists, but there are few controlled trials. The authors favour the use of both pharmacoand psychotherapy, though the latter is now usually more eclectic and cognitively based than the quasi-mystical psychoanalysis that formerly prevailed.

This book is noteworthy for its paucity of jargon and lucid style, enlivened by the literary quotations with which it is liberally sprinkled. Although the message conveyed is one of promise rather than achievement, it contains much to educate and excite both psychiatrists and interested lay persons. The authors have set a valuable precedent and a high standard for future therapistsufferer publications.

Kenneth Davison Consultant Psychiatrist Emeritus, 10 Grange Road, Fenham, Newcastle upon Tyne NE4 9LD, UK. Email: kennethdavison@hotmail.com doi: 10.II92/bjp.bp.106.03277।

\section{Global Pharmaceuticals: Ethics, Markets, Practices}

Edited by Adriana Petryna, Andrew Lakoff \& Arthur Kleinman. Duke University Press. 2006. 3I2pp. $€ \mid 4.95$ (pb). ISBN 08223374IX

From the racism of the mental hygiene movement, through Nazi Germany's quest to create the 'master race', to the Soviet's use of psychiatry to help silence dissidents, psychiatry has always been vulnerable to being used as part of the state's tools for social control. The modern neo-liberal state is no exception. By individualising and commodifying mental health, the radical and liberating potential of psychiatry is neutralised. Neo-liberalism has arguably produced more misery and suffering than at any time in the past; however, once this suffering can be reduced to the effects of abnormal molecules, not only are the social dynamics rendered invisible, but enormous new potential markets for the pharmaceutical industry emerge.

This book illustrates the real value of an anthropological/sociological approach to understanding complex local dynamics. Many of the authors pay particular attention to how global pharmaceutical markets affect the poorest and most marginalised groups of the population. There is also a focus on the very different impact of two globally important groups of drugs antidepressants and retrovirals.

The influence of the profit motive of drug companies in shaping research, academic discourse and practice in medicine in general, and psychiatry in particular, is now widely recognised. David Healy illustrates how the increasing use of antidepressants for a wide variety of conditions represents a triumph of marketing over science. Kalman Applbaum investigates how drug companies have challenged beliefs and practices in Japan, in their efforts to increase sales of selective serotonin reuptake inhibitors (SSRIs) portraying Japanese practice as backward and politicising access to SSRIs by turning it into a human rights issue. Andrew Lakoff

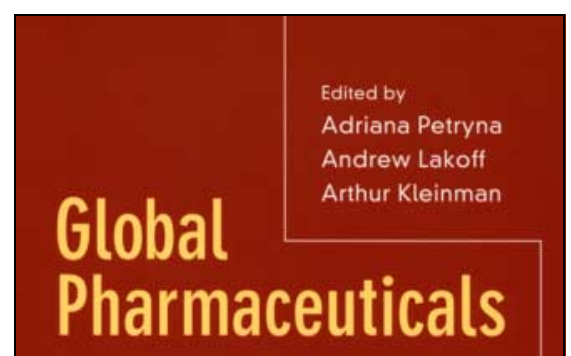

ETHICS, MARKETS, PRACTICES

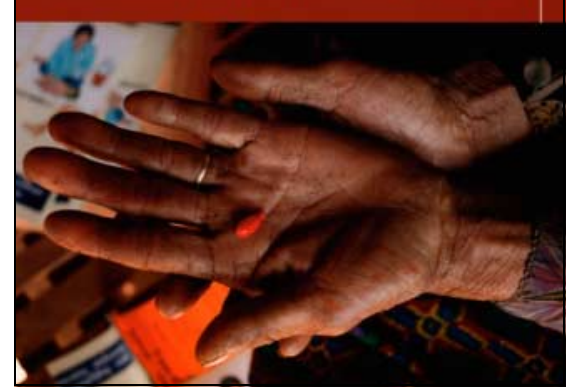

examines the very different market of Argentina, where some companies, realising that local and leading psychiatrists favoured a psychosocial approach, increased sales of their antidepressant after initiating a campaign to expose the 'hidden' issue of stress/ depression caused by economic insecurity following the recent economic collapse.

This is a must read for anyone who wants to understand the complex local nuances involved as neo-liberal globalisation increasingly redefines the location of human rights, justice and equity away from the social sphere and towards the individual body of the biotechnical citizen.

Sami Timimi Ash Villa Child and Adolescent Unit, Willoughby Road, Sleaford, Lincolnshire NG34 8QA, UK. Email: stimimi@talk2I.com

doi: 10.1192/bjp.bp.106.026369 